\title{
Correction to: Addressing vulnerability, building resilience: community-based adaptation to vector-borne diseases in the context of global change
}

Kevin Louis Bardosh ${ }^{1,2^{*}}$, Sadie J. Ryan ${ }^{2,3}$, Kris Ebi $^{4}$, Susan Welburn ${ }^{5}$ and Burton Singer ${ }^{2}$

\section{Correction}

After publication of this article [1] it came to our attention that the name of the author Sadie Ryan was incorrectly shown. Her correct name is Sadie J. Ryan. The original article has been updated to reflect this change.

\begin{abstract}
Author details
${ }^{1}$ Department of Anthropology, University of Florida, Gainesville, USA. ${ }^{2}$ Emerging Pathogens Institute, University of Florida, Gainesville, USA.

${ }^{3}$ Department of Geography, University of Florida, Gainesville, USA.

${ }^{4}$ Department of Global Health, University of Washington, Seattle, USA.

${ }^{5}$ Center of Infectious Disease, University of Edinburgh, Edinburgh, UK.
\end{abstract}

Received: 12 January 2018 Accepted: 12 January 2018

Published online: 30 January 2018

\section{Reference}

1. Bardosh KL, Ryan SJ, Ebi K, Welburn S, Singer S. Addressing vulnerability,

building resilience: community-based adaptation to vector-borne diseases in the context of global change. Infectious Diseases of Poverty 2017, 6:166. https://doi.org/10.1186/s40249-017-0375-2.

\footnotetext{
* Correspondence: bardosh_kevin@hotmail.com

${ }^{1}$ Department of Anthropology, University of Florida, Gainesville, USA

${ }^{2}$ Emerging Pathogens Institute, University of Florida, Gainesville, USA

Full list of author information is available at the end of the article
} 